\title{
Weight Bearing Asymmetry and Functional Ambulation Performance in Stroke Survivors
}

\author{
Dr. B. O. A. Adegoke (Corresponding author) \\ Physiotherapy Department \\ College of Medicine, University of Ibadan \\ Ibadan, Nigeria
}

Tel: 234-805-271-052Ｅ-mail: badegoke@comui.edu.ng

\& babatundeadegoke@yahoo.com

O. Olaniyi

Physiotherapy Department, Federal Medical Centre

Owerri, Nigeria

C. O. Akosile

Medical Rehabilitation Department, College of Health Sciences

Nnamdi Azikiwe University, Nnewi Campus

Awka, Anambra State, Nigeria

Received: November 30, 2011 Accepted: December 15, $2011 \quad$ Published: March 1, 2012

doi:10.5539/gjhs.v4n2p87 URL: http://dx.doi.org/10.5539/gjhs.v4n2p87

\begin{abstract}
This study evaluated asymmetry of weight bearing on the lower limbs and the association between percentage weight bearing asymmetry (PWBA) and functional ambulation performance in ambulant stroke survivors. Participants were 53 stroke survivors $($ male $=35$, female $=18$ ) aged 40-86 years (mean=58.87; SD=9.21years) with hemiparesis. Weight bearing through the lower limbs in standing was assessed by two juxtaposed bathroom weighing scales while functional ambulation performance was evaluated with the Emory Functional Ambulation Profile (E-FAP). Data were summarized with mean and standard deviation and further analyzed using the Pearson product moment correlation at 0.05 alpha level. Participants bore $60.3 \%(\mathrm{SD}=7.1 \%)$ of their body weights on the unaffected legs and had a mean PWBA of $20.8 \%(\mathrm{SD}=14.7 \%)$. There was a significant positive correlation $(r=0.675, \mathrm{p}<0.0001)$ between PWBA and total E-FAP scores of participants. PWBA could hence be used to monitor functional ambulation recovery in stroke survivors.
\end{abstract}

Keywords: Stroke survivors, Weight Bearing Asymmetry, Functional ambulation, Emory Functional Ambulation Profile

\section{Introduction}

Stroke is the third leading cause of morbidity and a major cause of long-term disability in the elderly (Bath, 2005). A high percentage of stroke survivors often experience long-term balance and mobility problems that may result in falls during rehabilitation or even after discharge from treatment (Falconer et al., 1994; Weedesteyn et al., 2008). Further, individuals with hemiparesis as a result of stroke often have difficulty accepting and bearing weight on the paretic leg hence they commonly exhibit asymmetry in standing and during ambulation with greater proportion of the body weight being borne on the non-paretic leg (Mercer, 2003). Distribution of body weight appears to be a significant factor influencing postural stability and one of the measures of balance used to quantify the extent of deficiency in postural control in stroke survivors (Nichols, 1997). Walking dysfunction is the most commonly reported limitation after stroke (Bohannon et al., 1988) and can markedly affect independence, quality of life, and participation (Schmid et al., 2007). 
There is no consensus as to the percentage of the body weight which is borne on the affected leg in stroke survivors though it has been generally reported that the unaffected leg bears a disproportionately greater proportion of the weight than the affected leg; a phenomenon known as Weight Bearing Asymmetry (WBA). The percentage of the body weight that is borne by the unaffected leg of the stroke survivor has hence variously been put at 61\% (Sackley et al., 1992), 63\% (Caldwell et al., 1986), and 70\% (Shumway-Cook et al., 1998, Mizrah et al., 1989). Sacley et al. (1992) further submitted that the unaffected leg may bear as much as $90 \%$ in severely affected individuals. Percentage WBA was found by Nichols (1997), to be up to $27 \%$ while Sorinola (2000), reported the percentage WBA in a similar study to be between $23.6+15.0 \%$ and $21.0+8.4 \%$.

Functional ambulation is the ability of a person to walk with maximal independence while spending the shortest time under various environmental circumstances. Although there is no established or gold criterion specifically for the assessment of ambulation, there are tests for gait speed (Wolf, et al., 1999). Gait speed has hence been used to evaluate stroke disability and walking recovery, estimate future health status and function, and predict level of community ambulation in stroke patients (Wade et al., 1992; Lord et al., 2004; Schmid, et al.. 2007) and as the primary outcome measure of rehabilitation in stroke patients (Wade et al., 1992). Goldie et al. (1996) reported that walking ability is markedly compromised following stroke and that majority of stroke survivors who regain their walking ability fail to achieve a normal walking speed of $1.2 \mathrm{metres}$ per second; the speed demonstrated by healthy adults. Ambulation performance has been assessed by the timed 10-metre walk test by various authors (Miller et al., 2002; Dean et al., 2000; Wolf et al., 1999). However, though, the timed 10-metre walk test is a valid test of mobility, it does not typically test the ability to move round obstacles and over different terrains (Wolf et al., 1999). It thus has limited applicability since an assessment of ambulation should include environmental variables encountered in daily living such as different terrains, obstacles and stairs (Robinett and Vondrain, 1988). An example of a clinically based measure is the Functional Ambulation Profile (FAP), which is a timed walking test specifically designed to track the progress of patients with neurological impairment (Perry et al., 1995).

Previous studies have investigated the correlations between WBA, gender, motor function and period since onset of stroke (Adegoke and Akinkoye, 2003), WBA and rate of fall (Cheng et al., 2001), WBA, functional ability and selected gait parameters (Adebisi, 2003) and WBA, motor function recovery and functional ability (Sorinola, 2000). The influence of WBA on stroke survivors' ability to negotiate obstacles and move over different terrains (functional ambulation performance) has not received much attention in literature. This is important in a country like Nigeria where many communities are unpaved and trekking is the most common mode of transportation in the rural areas and among the poor. This study therefore investigated WBA in a group of hemiparetic stroke survivors and the relationship between Percentage Weight Bearing Asymmetry (PWBA) and functional ambulation performance assessed using the Emory Functional Ambulation Profile (E-FAP)

\section{Research Methods}

\subsection{Subjects}

Fifty three consecutive patients (35 males and 18 females) of ages 40-86 years who had hemiparesis post-cerebrovascular disease (CVD) and were receiving physiotherapy treatment at the University College Hospital (UCH), Ibadan, Ring Road State Hospital, Ibadan, Lagos University Teaching Hospital (LUTH) and Lagos State University Teaching Hospital (LASUTH), Lagos at the time of data collection participated in this ex-post facto study. All participants met the following inclusion criteria:

1. No visual or hearing problem.

2. No other neurological problem apart from stroke.

3. No orthopaedic problems of the lower limbs that may affect lower limb function.

4. Able to understand (comprehend) and follow instructions.

\subsection{Instruments}

Instruments for data collection comprised two bathroom weighing scales (Hana, Germany) and the Emory Functional Ambulation Profile (E-FAP). The E-FAP has been reported to have high construct and concurrent validity, inter-rater reliability $\geq 0.997$ and test-retest reliability $\geq 0.998$ for the five sub-tasks. 


\subsection{Procedure}

The study was subject to the approval of the University of Ibadan/University College Hospital Institutional Review Committee on human subject research. Subjects also gave their informed consent while the managements of the hospitals where the data were collected permitted the conduct of the study.

Age and sex of each subject were recorded. Two bathroom weighing scales were then checked for accuracy against standard metal weights to ensure that the position of a load on the scale had no effect on the reading obtained as suggested by Caldwell et al. (1986). Each subject was then requested to stand on one of the weighing scales to measure the total body weight in kilograms to the nearest kilogram. The two scales were used alternately for total weight measurement to avoid overusing either of them. The two weighing scales were then juxtaposed at $10 \mathrm{~cm}$ distance apart and at a distance of 2 meters from the wall (Caldwell et al. 1986) and the subjects instructed to stand as erect as possible while placing one foot on each scale and looking forward. The weight on each scale was read off and recorded. Three trials were conducted for each subject with the subject stepping off the scales between trials to allow the scales return to zero. The mean of the three readings of each weighing scale were calculated for each limb and taken as the weight borne on that lower limb. Percentage weight bearing asymmetry (PWBA) was then calculated according to the following formula:

PWBA $=[($ Weight on the unaffected leg - weight on the affected leg $) /$ Total Body Weight $] \times 100$ (Nichols, 1999).

Subjects were then timed as they performed the five tasks of E-FAP namely: 5-metre walk on hard surface, 5-metre walk on carpeted surface, up- and- go, obstacle negotiation, and ascending/descending stairs. The time taken to complete each task was recorded as the score for each task while the total time taken to complete all the tasks represented the total profile (E-FAP) score (Wolf, et al., 1999). All E-FAP evaluations were carried out by one of the researchers $(\mathrm{OO})$ to eliminate inter-rater variations.

\subsection{Data Analysis}

Data were analysed using descriptive statistics of mean, standard deviation and percentages while Pearson product moment correlation method was used to investigate associations among PWBA, task scores and total E-FAB score at 0.05 alpha level.

\section{Analysis Result}

The subjects' parameters and comparison between the parameters of male and female subjects are presented in Table 1. Subjects' mean age and body weight were $58.87 \pm 9.21$ years and $70.51+11.0 \mathrm{~kg}$ respectively. Percentage weight bearing on the unaffected leg was $60.3 \pm 7.1 \%$ (range $=50.9-78.6 \%$ ) and all subjects bore more weight on their unaffected leg. The mean PWBA of the subjects was $20.8+14.7 \%$ (range $=1.4-57.1 \%$ ) and the mean time since stroke was $13.58 \pm 14.13$ months (range $=1-60$ months). Mean PWBA for first, second and third trials were $20.86 \pm 14.82,20.72 \pm 14.56$, and $20.91 \pm 14.72$ respectively with corresponding percentage coefficient of variations $(\% \mathrm{CV})$ of $71.04 \%, 70.3 \%$, and $70.4 \%$ for the respective trials. Male and female subjects did not differ significantly on any of the parameters. The total E-FAP and five subtask scores of the subjects are presented in Table 2. The mean total E-FAP score of the subjects was $91.82+41.45$ seconds (range $=44.8-22.31$ seconds). The lowest mean score (best performance) of $10.40+6.87$ seconds was recorded for the 5-metre walk on hard surfaced floor task while the highest mean score (worst performance) of $32.95+11.99$ seconds was recorded with the obstacle negotiating task.

Correlations among PWBA, total E-FAP score, and subtask scores are presented in Table 3. There were significant positive correlations between PWBA and the total E-FAP score $(\mathrm{r}=0.675, \mathrm{p}<0.0001)$ as well as between PWBA and each of the E-FAB subtask scores $(r \geq 0.509, p<0.0001)$. The correlation $(r=0.749)$ between PWBA and the total E-FAP score was higher than the correlations between PWBA and the subtasks' scores $(r \geq 0.561)$.The highest correlation $(r=0.680)$ was obtained between PWBA and the "up-and-go" subtask while the least correlation $(\mathrm{r}=0.509)$ was between E-FAB and the "obstacle negotiation" subtask. There were also significant positive correlations between the scores on the different subtasks; the highest correlation ( $\mathrm{r}=$ 0.961 ) occurring between scores on the "5metre-walk on the carpeted floor" and scores on "up-and-go" task. The least correlation ( $\mathrm{r}=0.528)$ was obtained between scores on both " 5 -meter walk on the hard floor" and "5meterwalk on carpeted floor" and scores on "obstacle negotiating" task. There were also indirect but not significant correlations between time since stroke and both PWBA and E-FAP score.

\section{Discussion}

This study investigated weight bearing asymmetry in standing in a cohort of ambulant hemiparetic stroke survivors and the correlation between percentage weight bearing asymmetry and functional ambulation 
performance. Functional ambulation was assessed using the Emory Functional Ambulation Profile (E-FAP). All the subjects $(100 \%)$ in this study bore more weight on their unaffected leg. This percentage is higher than the 93\% reported by Adegoke and Akinkoye (2003) and the $80 \%$ by Bohannon and Larking (1985) and Caldwell et al. (1986). However, subjects in this study bore a mean of $60.3 \%$ of their body weight on their unaffected leg which is similar to the $63.4 \%$ and $61.0 \%$ reported by Caldwell et al. (1986) and Sackley et al. (1992) respectively, but lower than the 70.0\% reported by Shumway- Cook et al. (1988) and Mizrahi et al. (1989) and higher than the $57.6 \%$ reported by Adegoke and Akinkoye (2003). Guillebastre et al. (2011) opined that the probability of a stroke survivor walking without a cane is less than $5 \%$ when the paretic lower limb is not loaded more than $40 \%$. This implies that an average participant in this study may not require a cane. The mean PWBA of $20.81 \%$ observed in this study is similar to the $23.64 \%$ and $21.02 \%$ reported for the two groups of hemiparetic subjects in the work of Sorinola (2000). The differences in the values of PWBA reported by the different studies might be a reflection of the severity of the stroke (Sackley, 1990) and/or how soon after the onset of the hemiplegia the subjects were evaluated for asymmetry. Expectedly, as submitted by Caldwell et al., (1986), long-standing cases would have received variable amounts of treatment that might include instruction on weight transfer through the affected leg and a consequent possibility of reacquiring some degree of ability to redistribute weight on the hemi-paretic leg. Subjects in this study have suffered stroke for 1-60 months and must have been receiving varying amount and quality of physiotherapy before taking part in this study though the amount of physiotherapy which subjects have received before taking part in this study was not considered as a variable. However, although measures of gait symmetry (swing time, stance time and step length) have been reported to demonstrate a systematic linear trend to greater asymmetry in the later stages poststroke, velocity, neurological deficit and lower extremity motor impairment did not (Patterson et al., 2008).

Slight variations were observed between the mean PWBA obtained during the three trials. Considering the stability of the scores obtained for the three trials, it may not be necessary to subject patients to such trials in clinical settings. However, the coefficients of variation obtained suggest considerable variations among participants that may be reflective of their stages of recovery. The PWBA and \%CV were lowest for the second trial and highest for the third trial thus suggesting that two trials may be optimum. It is plausible that participants were learning during the first trial while some degree of fatigue might have set in during the third trial.

The mean total E-FAP score of 91.82 seconds observed in our subjects was lower than the 103.51 seconds reported by Baer and Wolf (2001). As with weight-bearing asymmetry, we suspect that the severity of the initial stroke and how soon after the stroke the subjects were evaluated for functional performance could have been responsible for the observed differences. The lower the E- FAP score, the better the functional performance of stroke survivors. There was a statistically significant positive correlation between PWBA and E-FAP scores which implies that as the PWBA decreases, subjects improve in their functional ambulation performance and as a result, the time taken by subjects to complete ambulatory tasks (E.FAP score) reduces. Sackley et al. (1990) had earlier submitted that the observed weight bearing asymmetry (WBA) in hemparetic stroke subjects correlated significantly with motor function and functional activities of daily living while Sackley et al. (1992) concluded that WBA is linked with impaired motor function and in turn with decreased functional ability in stroke patients. Winstein (1989) had similarly observed that WBA was positively correlated with walking ability.

There were significantly positive correlations between the PWBA and participants' mean total EFAP and subtask EFAP scores. The correlations were weakest between PWBA and scores on the obstacle $(\mathrm{r}=0.561)$ and stairs $(\mathrm{r}=0.625)$ subtasks which are subtasks that involve activities that are more challenging than level walking. Cromwell and Wellmon (2001), Nadeau et al. (2003) and Troy and Grabiner (2005) had variously shown the increased challenge of stairs' ascent and descent compared to level walking and that the obstacle task requires quick restoration of dynamic balance. To maintain balance in the two tasks, the direction of body segments changes while kinematics and kinetics including weight bearing asymmetry are considerably higher than for level walking (Cromwell and Wellmon, 2001). Changes in the E-FAP scores may hence not be expected to have as much effect on performances on the obstacle and stair subtasks as on the other subtasks. This submission is supported by the findings from this study that the obstacle subtask score correlates only strongly with the total EFAP score and just fairly with other subtasks. It appears that poststroke individuals require bearing more weight on their unaffected limbs during the obstacle and stairs subtasks than they would during the performance of the other EFAP subtasks. We therefore suggest that exercises or treatment approaches aimed at influencing dynamic balance restoration should be included in poststroke management to facilitate better gait in the performance of the stairs and more importantly the obstacle subtasks. This position is supported by Hesse et al. (1995) and Akosile (2008). This recommendation will be in tandem with the suggestion by Genthon et al. (2008) that weight bearing asymmetry may not be the principle target of rehabilitation programs aimed at restoring 
standing balance after stroke since weight bearing asymmetry of standing stroke patients is not the primary cause of postural imbalance but a consequence of impaired control of postural stabilization involving both limbs.

We recommend that future studies evaluating therapy effectiveness in stroke using the EFAP should also use PWBA as an outcome measure and correlate this with EFAP scores at both pretest and posttest. This may indicate the extent to which our conclusions are justifiable.

\subsection{Clinical implication}

This study has shown that as the PWBA decreases, the E-FAP scores of subjects decrease; a low E-FAP score being an indication of a high functional ambulation performance. The PWBA can be used to monitor the response of post stroke hemiplegic patients to rehabilitation programs generally and functional ambulation performance specifically. The current practice whereby physiotherapists set the goal of achieving symmetrical weight distribution in their stroke patients is hence justified. The evaluation of PWBA does not require any sophisticated equipment and can be accommodated by the schedule of a busy physiotherapy clinician.

\section{References}

Adegoke, B. O. A., \& Akinkoye, O. O. (2003). The relationships between gender, motor function, period since stroke and assymmetry of lower limb weight distribution post-stroke. South African Journal of Physiotherapy, $59(3), 15-18$.

Akosile, C. O. (2008). Comparative effects of proprioceptive neuromuscular facilitation technique and conservative physical therapy on the functional ambulation of post-stroke individuals.Unpublished $\mathrm{PhD}$ Thesis, University of Ibadan, Department of Human Kinetics and Health Education.

Bath, P. M. W. (2005). Prostacyclin and analogues for acute ischeamic stroke (Systematic Review). Cochrane Stroke Group Cochrane Database of Systematic Reviews I.

Bear, H. R., \& Wolf, S. L. (2001). Modified Emory Functional Ambulation Profile (mE-FAP): an outcome measure for the rehabilitation of post-stroke gait dysfunction. Stroke, 32 (4), $973-979$.

Bohannon, R., \& Larking, P. (1985). Lower extremity weight bearing under various standing conditions in independently ambulatory patients with hemiparesis. Physical Therapy, 65 (9), $1323-1325$.

Bohannon, R. W., Andreus, A. W., \& Smith, M. B. (1988). Rehabilitation goals of patients with hemiplegia. International Journal of Rehabilitation Research, 11, 181-183.

Caldwell, C., McDonald, D., McNeil, K., et al. (1986). Symmetry of weight distribution in normal and stroke patients using digital weight scales. Physiotherapy Practice, 2, 109-116.

Cheng, P. T., Wu, S. H., Liaw, M. Y., et al. (2001). Symmetrical body-weight distribution training in stroke patients and its effect on fall prevention. Archives of Physical Medicine and Rehabilitation, 82, 1650-1654. http://dx.doi.org/10.1053/apmr.2001.26256

Cromwell, R., \& Wellmon, R. (2001). Sagital plane head stabilization during level walking and ambulation on stairs. Physiotherapy Reseach International, 6 (3), 179-192. http://dx.doi.org/10.1002/pri.226

Dean, C. M., Richards, C. L., \& Malouin, F. (2000). Task-related circuit training improves performance of locomotor tasks in chronic stroke: a randomized, controlled pilot trial. Archive of Physical Medicine and Rehabilitation, 81, 409-417. http://dx.doi.org/10.1053/mr.2000.3839

Falconer, J., Naughton, B., Strasser, D., et al. (1994). Stroke in-patient rehabilitation: a comparison across age groups. Journal of American Geriatric Society, 42, 39-44.

Genthon, N., Rougier, P., Gissot, A., et al. (2008). Contribution of each lower limb to upright standing in stroke patients. Stroke, 39 (6), 1793-9. http://dx.doi.org/10.1161/STROKEAHA.107.497701

Goldie, P. A., Matyas, T. A., \& Evans, O. (1996). Deficit and change in gait velocity during rehabilitation after stroke. Archives of Physical Medicine and Rehabilitation, 77, 1074-1082. http://dx.doi.org/10.1016/s0003-9993 (96)90072-6

Guillebastre, B., Rougier, P. R., Sibille, B., et al. (2011). When might a cane be necessary for walking following a stroke? Neurological Neural Repair. http://dx.doi.org/10.1177/154596831412786

Hesse, S. A., Bertelt, C. M., Jahnke, M. T., et al. (1995). Treadmill training with partial body weight support compared with physiotherapy in non-ambulatory hemiparetic patients. Stroke, 26 (5), 976-981. http://dx.doi.org/10.1161.01.STR.26.6.976 
Lord, S. E., McPherson, K., McNaughton, H. K., et al. (2004). Commnity ambulation after stroke: how important and obtainable is it and what measures appear predictive? Archives of Physical Medicine and Rehabilitation, 85, 234-239. http://dx.doi.org/10.1016/j.apmr.2003.05.002

Mercer, V. S., Cavanaugh, J., McCulloch, K., et al. (2003). Recovery of paretic lower extremity loading and weight transfer ability in individuals who are post-stroke. The Centre for Human Movement Science - UNC Charpel Hill. [Online] Available: www.med.unc.edu/chms/ProjectsStr.htm.03/01/2005

Miller, E. W., Quinn, M. E., \& Seddon, P. G. (2002). Body weight support treadmill and overground ambulation training for two patients with chronic disability secondary to stroke. Physical Therapy, 82 (1), 53-61.

Mizrahi, J., Solzi, P., Ring, H., et al. (1989). Postural Stability in Stroke patients: vectorial expression of asymmetry, sway activity and relative sequence of reactive forces. Medical Biology English Compact, 21, 181-90. http:dx.doi.org/10.1007/BF02446228

Nadeau, S., McFadyen, B. J., \& Malouin, F. (2003). Frontal and sagital plane analyses of the stair climbing task in healthy adults aged 40 years: What are the challenges compared to level walking? Clinical Biomechanics, 18 (10), 950-959.

Nichols, D. S. (1997). Balance Retraining after stroke using force platforms biofeedback. Physical Therapy, 77, $553-558$.

Obembe, A. O., Olaogun, M. O., \& Adedoyin, R. A. (2010). Gait characteristics of hemiparetic stroke survivors in Osun State, Nigeria. African Journal of Physical, Health Education, Recreation, Sport and Dance, 16 (4), 545-557.

Patterson, K. K., Gare, W. H., Brooks, D., et al. (2008). Changes in gait symmetry and velocity after stroke: A cross-sectional study from weeks to years after a stroke. Neurorehabilitation and Neural Repair, 24 (9), 783-790. http://dx.doi.org/ 10.1177/1545968310372091

Perry, J., Garrett, M., Gronley, J. K., et al. (1995). Classification of walking handicap in the stroke population. Stroke, 26, 982 - 989. http:dx.doi.org/10.1161/01/STR.26.6.982

Robinett, C. S. \& Vondran, M. A. (1988). Functional ambulation velocity and distance requirements in rural and urban communities: a clinical report. Physical Therapy, 68, 1371-1373.

Sackley, C. M. (1990). The relationship between weight bearing asymmetry after stroke, motor function and activities of daily living. Physiotherapy Theory and Practice, 6, 179-185. http:dx.doi.org/10.1016/S0031-9406 (10) 60498-1

Sackley, C. M., Baguley, B. I., Gent, S., et al. (1992). The use of a balance performance monitor in the treatment of weight-bearing and weight transferance problems after stroke. Physiotherapy, 78 (12), $907-913$.

Schmid, A., Duncan, P. W., Studenski, S., et al. (2007). Improvements in speed-based gait classifications are meaningful. Stroke, 38 (7), 2096-2100.

Shumway-Cook, A., Anson, D., \& Halter, S. (1988). Postural Sway Biofeedback: Its effect on re-establishing stability in hemiplegic patients. Archives of Physical Medicine and Rehabilitation, 69, 395-400. http:dx.doi.org/10.1161/STROKEAHA.106.475921

Sorinola, I. O. (2000). Effect of Balance Training on Weight Bearing Asymmetry, Motor Function Recovery and Functional Ability in Stroke Patients. Unpublished M.Sc. Dissertation of the Department of Physiotherapy, University of Ibadan.

Troy, K. L., \& Grabiner, M. D. (2005). The presence of an obstacle influences the stepping response during induced trips and surrogate tasks. Experimental Brain Research, 161, 343-350. http:dx.doi.org/10.1007/S00221. 004-2018-8

Wade, D. T., Gollen, F. M., Robb, G. F., et al. (1992). Physiothreapy intervention late after stroke. British Medical Journal, 304, 609 - 613. http:dx.doi.org/10.1136/bmj.304.6827.609

Weerdesteyn, V., de Niet, M., van Duijnhoven, H. J. R., et al. (2008). Falls in individuals with stroke. Journal of Rehabilitation Research \& Development, 45 (8), 1195-1214. http:dx.doi.org/10.1682/JRRD.2007.09.0145

Wolf, S. L., Catlin, P. A., Gage, K., et al. (1999). Establishing the reliability and validity of measurements of walking time using the Emory Functional Ambulation Profile. Physical Therapy, 79 (12), 1122-1133. 
Table 1. Characteristics of subjects

\begin{tabular}{llllll}
\hline \multicolumn{1}{c}{ Variable } & $\begin{array}{l}\text { All subjects } \\
(\mathrm{n}=53)\end{array}$ & $\begin{array}{l}\text { Male subjects } \\
(\mathrm{n}=34)\end{array}$ & $\begin{array}{l}\text { Female subjects } \\
(\mathrm{n}=19)\end{array}$ & $95 \% \mathrm{CI}$ & $\mathrm{p}$ \\
& $\mathrm{X} \pm \mathrm{S} . \mathrm{D}$ & $\mathrm{X} \pm \mathrm{S} . \mathrm{D}$ & $\mathrm{X} \pm$ S.D & & \\
\hline Age (years) & $58.87 \pm 9.21$ & $59.56 \pm 9.45$ & $57.63 \pm 8.87$ & -3.39 to 7.24 & 0.470 \\
Height (meters) & $1.66 \pm 0.08$ & $1.65 \pm 0.08$ & $1.67 \pm 0.09$ & -0.07 to 0.03 & 0.487 \\
Weight $(\mathrm{kg})$ & $70.51 \pm 11.01$ & $71.00 \pm 11.61$ & $69.93 \pm 10.09$ & -5.01 to 7.75 & 0.669 \\
BMI $\left(\mathrm{kg} / \mathrm{m}^{2}\right)$ & $25.58 \pm 3.66$ & $25.91 \pm 3.77$ & $24.98 \pm 3.47$ & -1.18 to 3.04 & 0.379 \\
TSS (months) & $13.58 \pm 14.13$ & $15.97 \pm 15.86$ & $9.32 \pm 9.25$ & -1.33 to 14.64 & 0.100 \\
PWA & $39.60 \pm 7.36$ & $38.74 \pm 7.81$ & $41.72 \pm 6.36$ & -6.60 to 1.84 & 0.262 \\
PWU & $60.40 \pm 7.36$ & $61.26 \pm 7.81$ & $58.88 \pm 6.36$ & -1.84 to 6.60 & 0.262 \\
PWBA & $20.85 \pm 14.67$ & $22.59 \pm 15.56$ & $17.75 \pm 12.73$ & -3.57 to 13.25 & 0.253
\end{tabular}

NB:

TSS $=$ Time since stroke

$\mathrm{BMI}=$ Body mass index

PWA $=$ Percentage weight on affected leg

PWU $=$ Percentage weight on unaffected leg

PWBA $=$ Percentage weight bearing asymmetry

Table 2. Emory Functional Ambulation Profile (E-FAP) scores of subjects

\begin{tabular}{llcc}
\hline \multicolumn{2}{c}{ Variable } & Range & $\mathrm{X} \pm$ S.D \\
\hline 5m-HF & (seconds) & $3.82-34.0$ & $10.4 \pm 6.9$ \\
$5 \mathrm{~m}-\mathrm{CF}$ & (seconds) & $3.95-35.76$ & $11.6 \pm 7.9$ \\
UGT & (seconds) & $6.72-60.44$ & $20.0 \pm 11.5$ \\
ONT & (seconds) & $13.12-58.90$ & $32.4 \pm 12.1$ \\
ADS & (seconds) & $6.90-42.87$ & $16.7 \pm 8.7$ \\
E-FAP & (seconds) & $44.8-223.1$ & $91.8 \pm 41.5$ \\
\hline
\end{tabular}

NB:

$5 \mathrm{~m}-\mathrm{HF}=5$-metre walk on hard surfaced floor

$5 \mathrm{~m}-\mathrm{CF}=5$-metre walk on carpeted (rugged) floor

UGT $=$ Up-and-go task

ONT $=$ Obstacle negotiating task

ADS $=$ Task of ascending and descending stairs

$\mathrm{E}-\mathrm{FAP}=$ Emory Functional Ambulation Profile 
Table 3. Correlation matrix for all variables

\begin{tabular}{|c|c|c|c|c|c|c|c|c|c|c|c|c|}
\hline & $\mathrm{Ht}$ & $\mathrm{Wt}$ & WBL & WBR & $\begin{array}{l}5 \mathrm{~m}-\mathrm{H} \\
\mathrm{F}\end{array}$ & $\begin{array}{l}5 \mathrm{~m}-\mathrm{C} \\
\mathrm{F}\end{array}$ & $\begin{array}{l}\text { UP\& } \\
\text { GO }\end{array}$ & TSS & $\mathrm{NO}$ & ADS & $\begin{array}{l}\text { E-FA } \\
P\end{array}$ & $\begin{array}{l}\text { PW } \\
\text { BA }\end{array}$ \\
\hline $\begin{array}{l}\text { Heigh } \\
\mathrm{t}\end{array}$ & 1.000 & & & & & & & & & & & \\
\hline $\begin{array}{l}\text { Weig } \\
\text { ht }\end{array}$ & $\begin{array}{l}0.451 * \\
*\end{array}$ & 1.000 & & & & & & & & & & \\
\hline WBL & $0.298^{*}$ & $0.591 * *$ & 1.000 & & & & & & & & & \\
\hline WBR & $0.332 *$ & $0.761 * *$ & 0.058 & 1.000 & & & & & & & & \\
\hline $\begin{array}{l}5 \mathrm{~m}-\mathrm{H} \\
\mathrm{F}\end{array}$ & -0.090 & -0.128 & $\begin{array}{l}-0.470 \\
* *\end{array}$ & $\begin{array}{l}0.354 \\
* *\end{array}$ & 1.000 & & & & & & & \\
\hline $\begin{array}{l}5 \mathrm{~m}-\mathrm{C} \\
\mathrm{F}\end{array}$ & -0.112 & -0.145 & $\begin{array}{l}-0.450 \\
* *\end{array}$ & $\begin{array}{l}0.307 \\
* *\end{array}$ & $\begin{array}{l}0.919 \\
* *\end{array}$ & 1.000 & & & & & & \\
\hline $\begin{array}{l}\text { UP\& } \\
\text { GO }\end{array}$ & -0.065 & -0.097 & $\begin{array}{l}-0.506 \\
* *\end{array}$ & $\begin{array}{l}0.382 \\
* *\end{array}$ & $\begin{array}{l}0.961 \\
* *\end{array}$ & 0.865 & 1.000 & & & & & \\
\hline TSS & -0.022 & 0.171 & -0.195 & 0.020 & -0.211 & -0.159 & -0.175 & 1.000 & & & & \\
\hline $\mathrm{NO}$ & -0.029 & 0.109 & -0.251 & $\begin{array}{l}0.481 \\
* *\end{array}$ & $\begin{array}{l}0.528 \\
* *\end{array}$ & $\begin{array}{l}0.528 \\
* *\end{array}$ & $\begin{array}{l}0.587 \\
* *\end{array}$ & 0.066 & 1.000 & & & \\
\hline ADS & -0.027 & -0.011 & -0.336 & $\begin{array}{l}0.386 \\
* *\end{array}$ & $\begin{array}{l}0.830 \\
* *\end{array}$ & $\begin{array}{l}0.790 \\
* *\end{array}$ & $\begin{array}{l}0.833 \\
* *\end{array}$ & -0.249 & $\begin{array}{l}0.568 \\
* *\end{array}$ & 1.000 & & \\
\hline $\begin{array}{l}\text { E-FA } \\
P\end{array}$ & -0.083 & -0.064 & -0.458 & $\begin{array}{l}0.432 \\
* *\end{array}$ & $\begin{array}{l}0.945 \\
* *\end{array}$ & $\begin{array}{l}0.888 \\
* *\end{array}$ & $\begin{array}{l}0.951 \\
* *\end{array}$ & -0.161 & $\begin{array}{l}0.747 \\
* *\end{array}$ & $\begin{array}{l}0.895 \\
* *\end{array}$ & 1.000 & \\
\hline $\begin{array}{l}\text { PWB } \\
\text { A }\end{array}$ & -0.039 & -0.035 & -0.777 & $\begin{array}{l}0.569 \\
* *\end{array}$ & $\begin{array}{l}0.651 \\
* *\end{array}$ & $\begin{array}{l}0.601 \\
* *\end{array}$ & $\begin{array}{l}0.680 \\
* *\end{array}$ & -0.166 & $\begin{array}{l}0.509 \\
* *\end{array}$ & $\begin{array}{l}0.538 \\
* *\end{array}$ & $\begin{array}{l}0.675 \\
* *\end{array}$ & 1.000 \\
\hline
\end{tabular}

$\mathrm{WBL}=$ Weight borne on left lower limb, $\mathrm{WBR}=$ weight borne on right lower limb.

$5 \mathrm{~m}-\mathrm{HF}=5$ metre walk on hard floor, $5 \mathrm{~m}-\mathrm{CF}=5$ metre walk on carpeted floor

$\mathrm{UP} \& \mathrm{GO}=\mathrm{Up}$ and go task, $\mathrm{TSS}=$ Time since stroke, $\mathrm{NO}=$ Negotiating obstacle

$\mathrm{ADS}=$ Ascending and descending stairs, $\mathrm{E}-\mathrm{FAP}=$ Overall E-FAP score

PWBA = Percentage weight bearing asymmetry

$*=$ Significant correlation at 0.05 level (2-tailed)

$* *=$ Significant correlation at 0.01 level (2-tailed) 